\title{
BMJ Global Health Building local capacity for emergency coordination: establishment of subnational Public Health Emergency Operations Centres in Nigeria
}

To cite: Oyebanji 0 , Ibrahim Abba F, Akande OW, et al. Building local capacity for emergency coordination: establishment of subnational Public Health Emergency Operations Centres in Nigeria. BMJ Global Health 2021;6:e007203. doi:10.1136/ bmjgh-2021-007203

Handling editor Seye Abimbola

Received 18 August 2021 Accepted 8 October 2021

\section{Check for updates}

(c) Author(s) (or their employer(s)) 2021. Re-use permitted under CC BY-NC. No commercial re-use. See rights and permissions. Published by BMJ.

For numbered affiliations see end of article.

Correspondence to Oyeronke Oyebanji; oyeronke.oyebanji@ncdc.gov.ng

Oyeronke Oyebanji (D) , ${ }^{1}$ Fatima Ibrahim Abba, ${ }^{2,3}$ Oluwatosin Wuraola Akande (D) , ${ }^{4}$ Everistus Chijioke Aniaku, ${ }^{5}$ Anwar Abubakar, ${ }^{5}$ John Oladejo, ${ }^{5}$ Olaolu Aderinola, ${ }^{3}$ Emmanuel Benyeogor, ${ }^{5}$ Femi Owoeye, ${ }^{6}$ Patrick M Nguku, Valerie Nkamgang Bemo, ${ }^{8}$ Chikwe Ihekweazu ${ }^{1}$

\section{ABSTRACT}

Public Health Emergency Operations Centres (PHEOCs) provide a platform for multisectoral coordination and collaboration, to enhance the efficiency of outbreak response activities and enable the control of disease outbreaks. Over the last decade, PHEOCs have been introduced to address the gaps in outbreak response coordination. With its tropical climate, high population density and poor socioeconomic indicators, Nigeria experiences large outbreaks of infectious diseases annually. These outbreaks have led to mortality and negative economic impact as a result of large disparities in healthcare and poor coordination systems. Nigeria is a federal republic with a presidential system of government and a separation of powers among the three tiers of government which are the federal, state and local governments. There are 36 states in Nigeria, and as with other countries with a federal system of governance, each state in Nigeria has its budgets, priorities and constitutional authority for health sector interventions including the response to disease outbreaks. Following the establishment of a National PHEOC in 2017 to improve the coordination of public health emergencies, the Nigeria Centre for Disease Control began the establishment of State PHEOCs. Using a defined process, the establishment of State PHEOCs has led to improved coordination, coherence of thoughts among public health officials, government ownership, commitment and collaboration. This paper aims to share the experience and importance of establishing PHEOCs at national and subnational levels in Nigeria and the lessons learnt which can be used by other countries considering the use of PHEOCs in managing complex emergencies.

Disease outbreaks and other public health emergencies are often unpredictable and require a range of rapid intervention of response activities. As part of their obligation to the International Health Regulations (IHR 2005), member states are required to 'develop, strengthen and maintain their
Summary box

- The annual occurrence of infectious disease outbreaks in Nigeria requires the development of adequate and resilient response capacity at national and subnational levels.

- The establishment of Public Health Emergency Operations Centres (PHEOCs) at national and subnational level in Nigeria has contributed to improved coordination of outbreak preparedness and response activities

- The increased investment in public health interventions may lead to political interference as an unintended consequence; therefore, the development and implementation of such interventions should involve government advocacy and cooperation.

- The establishment of PHEOCs has allowed for effective coordination and efficient resource management including rapid reporting of surveillance data, organisation of resources, deployment of rapid response teams, risk and crisis communications.

capacity to respond promptly and effectively to public health risks and public health emergencies of international concern'. ${ }^{1}$

A public health emergency poses a substantial risk to human health (resulting in injuries, permanent or long-term disability and deaths) and socioeconomic activities. There is evidence from previous emergency response activities that the timely implementation of an Emergency Operations Centre (EOC) provides an essential platform for the effective management of public health emergencies. ${ }^{2}$

An EOC is a physical location for the coordination of information and resources to support incident management activities for 'any type of incident'. It could refer to a range of emergency management facilities, from an on-scene incident command post 
at an emergency site, to a national emergency coordination centre that provides strategic direction and resources to multiple jurisdictions and agencies in a wide area disaster. ${ }^{3}$ This concept was first used by the military, and later adopted by other sectors including public health. ${ }^{4}$

A Public Health Emergency Operations Centre (PHEOC) specialises in the command, control and coordination requirements of responding to emergencies that involve "health consequences and public health threats'. ${ }^{5}$ A Concept of Operations describes policies, roles and responsibilities and how the structural or functional elements of the organisation will work together for effective coordination of responding agencies from different sectors at multiple levels of the response. It uses the Incident Management System (IMS) to provide a management structure for coordinating the response and a set of protocols for operations, planning, logistics, finance and administration. ${ }^{6}$ These functions are then further expanded to pillars.

The earliest use of EOCs in Nigeria was with the national polio response. In 2012, donor-funded EOCs were established including a National Polio EOC and subsequently, state-level EOCs in states with the highest burden of polio cases. ${ }^{7}$ This was part of a programme to support the three polio-endemic countries at the timeAfghanistan, Pakistan and Nigeria-to eradicate polio. ${ }^{7}$ These EOCs played a vital role in Nigeria's attainment of wild polio-free status in August 2020.

With over 20 public health emergencies and infectious disease outbreaks between 2016 and 2018, Nigeria is one of only five member states of the WHO African Region to report five or more public health events per annum. ${ }^{9}$ Often, these public health emergencies happen simultaneously requiring multisectoral coordination. However, the polio EOCs in place focused solely on polio response and eradication activities.

Over the years, WHO member states have established PHEOCs to provide a platform for coordination, multisectoral collaboration and communication, to effectively prepare for, detect and respond to public health emergencies. ${ }^{10}$ In 2012, WHO and partners published the PHEOC framework to provide a structured approach to meeting the objectives of the Public Health EOC Network. The network recognises the importance of PHEOC capacity in countries and provides guidance and best practices towards developing this. ${ }^{11}$

The Global Health Security Agenda (GHSA) was launched in 2014 to support the implementation of the IHR. In particular, the GHSA has an EOC Action Package with a 5-year target to ensure "every country will have a public health EOC functioning according to minimum common standards; maintaining trained, functioning, multisectoral rapid response teams (RRTs), 'real-time' biosurveillance laboratory networks and information systems; and trained EOC staff capable of activating a coordinated emergency response within $120 \mathrm{~min}$ of the identification of a public health emergency'. ${ }^{12}$
The Nigeria Centre for Disease Control (NCDC), as the country's IHR National Focal Point, has the mandate to ensure capacity across the IHR technical areas. Recognising the importance of developing the capacity to coordinate disease outbreaks which occur frequently, NCDC established a National PHEOC in 2016 and began the process of establishing subnational PHEOCs across states in Nigeria in 2017. Within 3years, 28 out of 37 states $(75 \%)$, including the Federal Capital Territory (FCT) had established a functional subnational PHEOC. This paper aims to share the experience and importance of establishing PHEOCs at national and subnational level in Nigeria.

\section{INFECTIOUS DISEASE OUTBREAKS IN NIGERIA AND THE NEED FOR COORDINATION}

Nigeria is a federal republic with a presidential system of government. Its constitution provides for a separation of powers among the three tiers of government which are the federal, state and local governments. There are $36^{13}$ states and an FCT in Nigeria, and as with other countries with a federal system of governance, each state has its budgets, priorities and constitutional authority for health sector interventions. ${ }^{14}$ Health is on the concurrent list of the constitution, giving the federal, state and the local governments autonomous authority to legislate on health matters. ${ }^{15}$ This highlights the need for coordinated structures for disease outbreak preparedness and response.

The outbreaks of infectious diseases, occurring annually, strain the public health sector and cause significant economic and social setbacks. This may be related to the country's population density, tropical climate, poor socioeconomic indicators and other factors which enable the spread of disease. ${ }^{16}$

Between 2016 and 2017, there were approximately 40000 cases and 1000 deaths from outbreaks of six infectious diseases-Lassa fever, cerebrospinal meningitis, cholera, measles, monkeypox and yellow fever. It is estimated that the aggregated economic impact of these outbreaks was a cost of 3.8 billion naira (US $\$ 10.5$ million) in 1 year only. ${ }^{17}$ A clearly defined chain of command and organisational structure, effective resource management and advanced planning are important aspects of an emergency response ${ }^{15}$ However, the gaps in Nigeria's public health emergency coordination capacities as illustrated by the WHO Joint External Evaluation (JEE) and other assessments affected the response to disease outbreaks. ${ }^{18}$

In 2017, Nigeria conducted an evaluation of its IHR core capacities using the WHO JEE tool, coordinated by NCDC. The evaluation highlighted gaps in Nigeria's emergency response operations and structures, recommending activities to strengthen intersectoral collaboration for emergency response particularly between human, animal and environmental health, using a 'one health' approach at the national and subnational levels. ${ }^{18}$ 
For several years, Nigeria did not have a public health emergency coordination hub despite the occurrence of multiple, large disease outbreaks. This contributed to fragmented structures in coordinating outbreak response, with varying capacity across states.

\section{STRENGTHENING COORDINATION AND GOVERNMENT OWNERSHIP FOR DISEASE OUTBREAKS}

The IHR emphasises the importance of establishing PHEOCs where health leaders can receive information from multiple sources, coordinate decision-making, communicate across levels and sectors, and mobilise RRTs and resources. ${ }^{19}$ The IHR requires state parties to develop, strengthen and maintain their capacity to respond promptly and effectively to public health risks and public health emergencies. A functional PHEOC is an important component of meeting these requirements. ${ }^{20}$

PHEOCs provide platforms to use the IMS for outbreak coordination. Within the IMS, five essential functions namely: management, operations, planning, logistics and finance and planning are typically established, with the flexibility to adapt to different events, agencies and jurisdictions. ${ }^{2}$ These functions are then further expanded to pillars.

One of the important values that these EOCs present is multiagency coordination, serving as a platform for key stakeholders across various agencies to share information and participate in decision-making processes meeting global standards. ${ }^{1}$ So far, countries such as the USA, Australia, the UK, China and regions such as the European Union have established PHEOCs. Some of these have been established independently or as a part of the government response. ${ }^{21} 22$ Between January and July 2017, in response to the H7N9 outbreak, China CDC EOC coordinated departments to develop the epidemiological and laboratory testing strategy across 22 provinces through improved access and utilisation of the information via the EOC. ${ }^{23}$ In the USA, the CDC uses Emergency Management Programs similar to Nigeria's Technical Working Groups (TWGs) to ensure all key stakeholders in a response have a place in the overall response structures. ${ }^{24}$

The importance of coordination of public health emergency response in Nigeria was demonstrated by the role the polio EOCs played towards the elimination of the virus. It tremendously contributed towards the interruption of wild polio virus transmission until the country was certified wild polio-free after meeting all the criteria in $2020 .^{25-27}$

The polio EOCs and infrastructure became a springboard to use PHEOCs to contain the spread of the Ebola virus in Nigeria in 2014 using resources from the National Polio EOC to coordinate response. Despite this globally acclaimed success in containing the Ebola outbreak, the Nigerian Public Health Epidemic Preparedness and Response landscape remained complex and fragmented.
After the outbreak, the resources adopted from the polio programme were refocused to sustain the polio response. This meant there was limited coordination for the preparedness and response to other disease outbreaks. ${ }^{28}$

\section{ESTABLISHING A NATIONAL INCIDENT COORDINATION CENTRE}

The NCDC has the mandate to detect, investigate, prevent and control public health emergencies and enhance Nigeria's preparedness and response activities. ${ }^{29}$ In 2016 , NCDC established a 'situation room' as an avenue to analyse data and information available to direct response activities and facilitate collective informed decisionmaking. This was part of early steps to establish a National Incident Coordination Centre (ICC) ${ }^{30}$

The 2016/2017 meningitis outbreak in Nigeria led to the activation of the first IMS to manage and coordinate response activities within the situation room. While a situation room existed, the absence of a large space with the required audiovisual equipment affected the IMS capacity to fully implement its functions. Additionally, Nigeria's multiple and often concurrent disease outbreaks highlighted the need for a more expansive coordination structure-both in terms of physical space and capabilities. Following lessons learnt from the large 2016/2017 meningitis outbreak, including the value of a national coordination structure, and subsequent response activities to other disease outbreaks, a National PHEOC named the National ICC was established to institutionalise this process. ${ }^{30}$

The ICC serves as the hub for maintaining situational awareness, daily epidemiological intelligence gathering and risk analysis of emerging events of public health importance. When public health threats are identified, the hub supports the coordination of effective response operations combining information and communications technologies to inform decision-making. ${ }^{30}$

The ICC operates in three major modes-watch mode, alert mode and response mode. Through these modes, the ICC maintains a constant cycle of routine monitoring, situational awareness and clear pathway for rapid escalation. When there is a public health event or emergency, the ICC uses its Incident Activation Plan to define the level of response required. By using these modes and levels, the ICC remains active throughout the year. ${ }^{31}$ Since its establishment, the NCDC ICC has coordinated response activities to over 13 outbreaks and public health emergencies in Nigeria. These include meningitis, Lassa fever, yellow fever, monkeypox, measles outbreaks, and most recently, the COVID-19 pandemic. ${ }^{32}$ The use of an ICC has enabled better coordination of preparedness and response activities, including the deployment of RRTs, better visualisation of outbreak reports, triggering early response measures, as well as improved coordination of activities across various departments within NCDC and with other national and international health agencies and partners. ${ }^{29} 30$ 
In addition to the establishment of the ICC, NCDC established Disease TWGs to provide focus on the prevention, detection, surveillance and monitoring of the six epidemic prone diseases and other priority public health issues. ${ }^{334}$ The TWGs serve as a multisectoral platform for monitoring reports of cases and deaths, developing guidelines, making decisions for the prepositioning of supplies from medical countermeasures in the absence of a disease outbreak and other outbreak preparedness activities. These TWGs replicated the IMS structure in terms of functions and pillars, but within a non-emergency framework, meeting less frequently than the EOC. For example, a risk communications pillar ensures continued revision of information, education and communication materials, monitoring of media reports, training of health education officers among others. The establishment of TWGs ensures that both the ICC space and human resource capacity needed for outbreak response coordinated are active throughout the year.

The use of the TWG model and establishment of the ICC contributed to NCDC's improved capacity to manage multiple concurrent epidemics simultaneously, with allyear round activities that transitioned from preparedness to response.

\section{ESTABLISHING SUBNATIONAL PHEOCS IN NIGERIA}

Following the successful establishment of the ICC, NCDC began a similar process at subnational (state) level. The first phase of state PHEOC establishment began with a prioritisation exercise conducted using a desk review and on-site assessment of the 36 states and FCT of the federation. The assessment was done based on criteria including but not limited to the existence of a polio EOC, states' vulnerability to large outbreaks and commitment from the state government to sustain the centre. The engagement process with states involved a high-level advocacy visit to the state commissioner of health and agreement of a policy framework for preparedness and response activities. This was followed by the allocation of government-owned building to be used as a physical site for the EOC and the agreement in principle to fund its operations. The prioritised states for the first phase of the implementation were Ebonyi, Bayelsa, Cross River, Zamfara, Enugu and the FCT. These states did not have a polio EOC, had witnessed large outbreaks in the last year and were committed to providing the resources required to establish the PHEOCs.

Subsequently, the implementation of the State PHEOC was in three phases including: (a) the renovation of the designated PHEOC facility; (b) procurement and deployment of basic PHEOC equipment and (c) the provision of 10-day training on managing public health emergencies using PHEOCs.

To incorporate sustainability, each state was requested to allocate a government-owned building, preferably within the State Ministry of Health, to serve as its PHEOC. This also reduced the need for recurrent expenditure used to rent buildings and promoted integration within the existing health structure. The NCDC developed the PHEOCs criteria with minimum requirements for a standard PHEOC in states. This took into consideration existing difficulties in Nigeria such as interrupted power supply. For example, solar panels and inverter systems were installed to provide alternative power supply. Statelevel staff were trained on the basic principles of public health emergency management for 10 days by NCDC. The NCDC supported the states in developing several incident documents ranging from standard operating procedures, incident action/activation plan, emergency operations plans and templates for situation reports, after action review reports. Subsequently, the trained staff were mentored virtually via monthly meetings with NCDC.

As the State PHEOCs were introduced across the country, NCDC continued to improve the process of establishment. For example, residents of the Nigeria Field Epidemiology and Laboratory Training Programme were integrated as part of the establishment and mentorship process. As of March 2021, NCDC had established PHEOCs in 28 of Nigeria's 36 states and FCT; 10 of these were established during the COVID-19 pandemic.

\section{STRONGER COORDINATION THROUGH PHEOCS}

In Nigeria, PHEOCs are established using an IMS with the following pillars-coordination, surveillance/epidemiology, laboratory, risk communication, case management, research, logistics and supply chain. Additional pillars are activated depending on the disease, such as water, sanitation and hygiene for cholera outbreaks, and point of entry for COVID-19.

At the beginning of the COVID-19 pandemic, all the states with PHEOCs in Nigeria quickly activated these for coordination. These states had previous experience in coordinating other disease outbreaks, had existing staff for the functions required and a coordinated platform for partner coordination and resource mobilisation. The COVID-19 pandemic required a multisectoral response, which is a core component that most State PHEOCs had integrated. In states without PHEOCs, NCDC deployed its staff who supported rapid training on IMS, while responding to the pandemic.

The establishment of PHEOCs has proven to be valuable. Following a desk review of existing documents and interview of state epidemiologists and other stakeholders involved in the first roll-out of PHEOCs, we outline some of the benefits from this process in five major themes.

\section{Improved coordination}

There is an improved level of coordination in responding to outbreaks. The PHEOCs have the function of coordinating emergency preparedness and response activities which include data collection and analysis, information management, personnel deployment and resource allocation. 
With the existence of PHEOCs, additional resources from the government or partners are managed within an existing hub and led by the state government. For example, the gradual rollout of Surveillance and Outbreak Response Management System as a tool for digital surveillance has been coordinated within State PHEOCs, rather than in the core ministry where bureaucracy can lead to delays. In most states, security agencies, traditional and religious leaders, who do not necessarily work within the Ministry of Health, supported outbreak response activities through the PHEOC.

Additionally, the turnaround time from detection of an outbreak to initiation of response activities has declined from an average of 10 days to 3 days since the establishment of PHEOCs according to analysis carried out by NCDC. ${ }^{35}$

The establishment of these PHEOCs has also enabled interagency collaboration during outbreaks requiring multiple actors. For example, in 2018, the Edo State PHEOC was used to coordinate the response to a yellow fever outbreak which included a reactive vaccination campaign. ${ }^{36}$ The vaccination campaign was led by the National Primary Health Care Development Agency (NPHCDA), and the PHEOC provided a coordination platform for the state and multiple health agencies including NCDC and NPHCDA. A similar model of coordination among several actors has continued through the PHEOCs, including for the COVID-19 response.

\section{Improved coherence of thoughts}

Prior to the implementation of the PHEOC, public health staff working in disease outbreak departments were performing most of the same tasks that they are now performing within PHEOCs. One key difference that exists pre-PHEOC and post-PHEOC establishment is the holistic approach provided from working within PHEOCs. This means staff are more aware of developing actions that have clear outputs and a pathway towards this. One state epidemiologist described having a PHEOC as a 'more structured, more organised and more deliberate' way of working.

\section{Improved commitment}

Most state-level staff have shown improved commitment to their roles and functions, associating this with the training provided during the establishment of PHEOCs. According to those interviewed, they are better informed about the importance of their roles and measures towards performing these. This has enabled an improved sense of ownership and therefore commitment to public health preparedness and response activities.

\section{Improved collaboration}

In some states, the PHEOCs are now being used beyond infectious disease outbreak preparedness and response, for other public health activities. For example, some PHEOCs are used for the coordination of maternal, newborn and child health interventions. This has enabled further collaboration to integrate health security and achieve universal health coverage for improved health in Nigeria.

\section{Improved government ownership}

One of the challenges identified in Nigeria's health system is poor donor coordination. ${ }^{13}$ Donors tend to commit resources to similar activities, resulting in duplication of effort, a waste of resources and missed opportunities. Additionally, donors have supported activities without ownership or sustainability processes agreed with the government. The PHEOCs have improved this as partners working in health security are aware of a structure led on by the government, preventing work in silos and fragmented response initiatives. During outbreaks, the appointment of an incident manager by the state government has also enabled state-government ownership and leadership of response activities.

\section{LESSONS LEARNT FROM THE ESTABLISHMENT OF SUBNATIONAL PHEOCS IN A FEDERAL COUNTRY}

While the establishment of PHEOCs in Nigeria has proven to be valuable in terms of coordination, collaboration and commitment, it has not been without challenges.

In recent times, there has been an increased interest from funders in providing technical and financial support to the operation of PHEOCs. Though anecdotal, it is also being politicised for political gains. A typical example is with the frequent posting and reposting of trained officials to other State Health Departments. This results in high staff turnover, with the need to keep training newly posted staff, thus interfering with public health response activities. To address this challenge, the NCDC continuously engages state governments in advocacy activities, soliciting their buy-in and support for response activities at the PHEOC in their jurisdiction.

Second, it is important to ensure that all the key functions of a PHEOC stipulated in the WHO's Framework for a PHEOC are adapted to context. Where functions have been left out, it was more likely to be the finance and administrative function, with detrimental effects for PHEOC functioning. The NCDC has continued to ensure the inclusion of these functions during the process of introducing PHEOC concepts and public health emergency management training.

One of the major challenges was the limited capacity of individuals with the knowledge and experience of IMS and PHEOCs. This required longer duration of deployment for NCDC staff, to train other state-level officials. One lesson from this process was that regular objectivebased training and simulation exercises at individual and organisational levels should be instituted at the early phase of the establishment to build skills, relationships and the understanding of the plans and procedures in place to support the response activities. Furthermore, establish train-the-trainer programme to enable stepping 
down of the training from NCDC thereby sustaining the capacity at state level.

Following the initial cost of establishment, recurrent expenditure for the PHEOCs was initially envisioned to be the responsibility of the state governments. However, the level of commitment has varied across the states leading to reviewing the requirement for ongoing financial support for the first 6 months to allow for state budgets adjustment.

The lessons learnt and challenges experienced served as a learning curve for scaling up the establishment of PHEOCs across the country and in similar settings.

\section{BUILDING BACK BETTER: THE ROLE OF PHEOCS}

The establishment of PHEOCs at the subnational level in Nigeria has proven to be extremely valuable. This has contributed to the COVID-19 pandemic response in Nigeria where an emergency management structure was introduced prior to the confirmation of cases. This approach allowed for effective coordination and efficient resource management including rapid reporting of data, organisation of resources, deployment of RRTs, risk and crisis communications. By having PHEOCs across states, there is less pressure on the national PHEOC led by NCDC during disease outbreaks.

Our experience provides formative elements, lessons and challenges from establishing subnational PHEOCs in a federal country with annual large disease outbreaks. If adopted, these could provide a route to better results in disease outbreak response coordination. While the elements of response coordination can aid performance monitoring in a formal PHEOC, best practices and pathways could be implemented even when there are not physical PHEOCs in existence.

Many countries face serious challenges in coordinating a multisectoral response to public health events. The use of PHEOCs can solve this challenge, towards stronger global health security. This is especially important as many countries reflect on the COVID-19 pandemic response and aim to build back better for future outbreaks and pandemics.

In conclusion, the effective coordination and improved control of outbreaks as evidenced by shorter times from detection to response is evidence that a functional PHEOC is valuable in the prompt containment of infectious disease outbreaks in large countries like Nigeria.

\section{Author affiliations}

${ }^{1}$ Office of the Director General, Nigeria Centre for Disease Control, Abuja, Federal Capital Territory, Nigeria

${ }^{2}$ Health Emergency Preparedness and Response, Public Health England, London, UK

${ }^{3}$ Nigeria Centre for Disease Control, Abuja, Federal Capital Territory, Nigeria

${ }^{4}$ Prevention, Programmes and Knowledge Management, Nigeria Centre for Disease Control, Abuja, Federal Capital Territory, Nigeria

${ }^{5}$ Health Emergency Preparedness and Response, Nigeria Centre for Disease Control, Abuja, Federal Capital Territory, Nigeria

${ }^{6}$ Independent Consultant, Nigeria Centre for Disease Control, Abuja, Federal Capital Territory, Nigeria
${ }^{7}$ Nigeria Field Epidemiology Training Programme, African Field Epidemiology Network, Abuja, Federal Capital Territory, Nigeria

${ }^{8}$ Global Development, Bill \& Melinda Gates Foundation, Seattle, Washington, USA

Twitter 0yeronke 0yebanji @0yeronke_,John 0ladejo @johnoladejo,Emmanuel Benyeogor@EIBenyeogor and Chikwe Ihekweazu@Chikwe_I

Acknowledgements The authors thank Abara Erim for his administrative support, and all state epidemiologists involved in the establishment of PHEOCs.

Contributors $00, F A$ and $0 A$ developed the concept for this paper. 00 wrote the first draft and all others reviewed subsequent drafts. All authors were involved in the project design, implementation and evaluation. $\mathrm{Cl}$ provided overall supervision and serves as guarantor of the project.

Funding Bill \& Melinda Gates Foundation Emergency Relief Grant OPP1192943.

Competing interests None declared.

Patient consent for publication Not required.

Ethics approval This study did not receive nor require ethics approval, as it does not involve human and animal participants.

Provenance and peer review Not commissioned; externally peer reviewed.

Data availability statement All data relevant to the study are included in the article.

Open access This is an open access article distributed in accordance with the Creative Commons Attribution Non Commercial (CC BY-NC 4.0) license, which permits others to distribute, remix, adapt, build upon this work non-commercially, and license their derivative works on different terms, provided the original work is properly cited, appropriate credit is given, any changes made indicated, and the use is non-commercial. See: http://creativecommons.org/licenses/by-nc/4.0/.

\section{ORCID iDs}

Oyeronke Oyebanji http://orcid.org/0000-0002-2935-2435

Oluwatosin Wuraola Akande http://orcid.org/0000-0001-6906-895X

\section{REFERENCES}

1 World Health Organization (WHO), Public Health Emergency Operations Centre Network (EOC-NET). Strengthening health security by implementing the International health regulations 2005 , 2021. Available: https://www.who.int/ihr/eoc_net/en/ [Accessed 10 May 2021].

2 WHO. Framework for a public health emergency operations centre. MMWR Morb Mortal Wkly Rep [Internet] 2015;50:35 www.who.int/ about/licensing/\%0Ahttps://apps.who.int/iris/bitstream/handle/ 10665/196135/9789241565134 eng.pdf?sequence=1

3 US Department of Health \& Human Services, Public Health Emergency. Emergency management and the incident command system [Internet], 2012. Available: https://www.phe.gov/ Preparedness/planning/mscc/handbook/chapter1/Pages/ emergencymanagement.aspx [Accessed 27 May 2021].

4 Holdeman E. EOC Versus ECC: Which term do you use - and why? [Internet], 2021. Available: https://www.govtech.com/em/ emergency-blogs/disaster-zone/eoc-versus-ecc.html [Accessed 13 Jun 2021].

5 W.H.O Africa Region. Integrated Disease Technical Surveillance and in the Who Integrated Disease Surveillance and. In: 4,5,6 and. 3rd Edition, 2019.

6 World Health Organization (WHO). WHO EOC-NET global webinar on Public Health Emergency Operations Centre (PHEOCs) for COVID-19 response [Internet], 2020. Available: https://www.who.int/ news-room/events/detail/2020/06/23/default-calendar/who-eoc-netglobal-webinar-on-public-health-emergency-operations-centre-forcovid-19-response [Accessed cited 2021 Sep 18].

7 Bristol N, Hussain I. Polio emergency operations centers [Internet], 2021. Available: https://www.csis.org/features/polio-emergencyoperations-centers [Accessed 27 May 2021].

8 World Health Organization. Who and UNICEF congratulate Nigeria on ending wild poliovirus; call for strengthening of routine immunisation, 2020. Available: https://www.afro.who.int/news/pressrelease-who-and-unicef-congratulate-nigeria-ending-wild-polioviruscall-strengthening

9 Olumade TJ, Adesanya OA, Fred-Akintunwa IJ, et al. Infectious disease outbreak preparedness and response in Nigeria: history, limitations and recommendations for global health policy and practice. AIMS Public Health 2020;7:736-57. 
$10 \mathrm{Xu} \mathrm{M}$, Li S-X. Analysis of good practice of public health emergency operations centers. Asian Pac J Trop Med 2015;8:677-82.

11 Nigeria Centre for Disease Control. COVID-19 outbreak response toolkit for state public health emergency operations centre, 2020. Available: http://ciheb.org/media/SOM/Microsites/CIHEB/Nigeria/ PHEOC_TOOLKIT_SOP_V4Print_Updated.pdf

12 Centers for Disease Control and Prevention (CDC). Global health security agenda: action packages [Internet], 2014. Available: http:// www.cdc.gov/globalhealth/healthprotection/ghs/pdf/ghsa-actionpackages_24-september-2014.pdf\%5Cnhttps://ghsagenda.org/ packages.html

13 Makinde OA, Meribole EC, Oyediran KA, et al. Duplication of effort across development projects in Nigeria: an example using the master health facility list. Online $J$ Public Health Inform 2018;10:e208.

14 Security.Org G. Nigerian Government [Internet], 2021. Available: http://www.globalsecurity.org/military/world/nigeria/government. htm

15 Pillai SK, Nyenswah T, Rouse E, et al. Developing an incident management system to support Ebola response -- Liberia, JulyAugust 2014. MMWR Morb Mortal Wkly Rep 2014;63:930-3.

16 Ihekweazu C. Investing in national public health institutes for future pandemics: lessons from Nigeria [Internet], 2021. Available: https:// www.brookings.edu/blog/africa-in-focus/2021/02/10/investing-innational-public-health-institutes-for-future-pandemics-lessons-fromnigeria/

17 Dalberg Advisors. Strengthening national capacity for public health emergency preparedness \& response: draft strategy annex for NCDC, 2018. Available: https://www.who.int/activities/ strengthening-national-emergency-preparedness

18 World Health organization. Joint external evaluation of IHR core capacities of the federal Republic of Nigeria, 2017. Available: https:// apps.who.int/iris/bitstream/handle/10665/259382/WHO-WHE-CPIREP-2017.46-eng. pdf?sequence=1\&isAllowed=y [Accessed $27 \mathrm{Sep}$ 2021].

19 Inglesby T, Fischer JE. Moving ahead on the global health security agenda. Biosecur Bioterror 2014;12:63-5. doi:10.1089/ bsp.2014.3314

20 World Health Organization. International health regulations (2005). 2 edn, 2008.

21 Balajee SA, Pasi OG, Etoundi AGM, et al. Sustainable model for public health emergency operations centers for global settings. Emerg Infect Dis 2017;23:S190-5.

22 World Health Organization (WHO). A systematic review of public health emergency operations centres (EOC), 2013. Available: https:// www.who.int/publications/i/item/a-systematic-review-of-publichealth-emergency-operations-centres-(-eoc)
23 Ding F, Li Q, Jin L-M. Experience and practice of the emergency operations center, Chinese center for disease control and prevention: a case study of response to the H7N9 outbreak. Infect Dis Poverty 2021:10. doi:10.1186/s40249-020-00789-x

24 US CDC. Emergency operations centers and incident management structure, 2020. Available: https://www.cdc.gov/eis/field-epi-manual/ chapters/EOC-Incident-Management.html [Accessed 18 Sep 2021].

25 Ado JM, Etsano A, Shuaib F, et al. Progress toward poliomyelitis eradication in Nigeria. J Infect Dis 2014;210 Suppl 1:S40-9.

26 Okeibunor J, Nsubuga P, Salla M, et al. Coordination as a best practice from the polio eradication initiative: experiences from five member states in the African region of the world Health organization. Vaccine 2016;34:5203-7. doi:10.1016/j.vaccine.2016.05.066

27 NPHCDA. Nigeria polio eradication emergency plan, 2019. Available: https://polioeradication.org/wp-content/uploads/2018/04/NigeriaNational-Polio-Emergency-Plan-2018.pdf

28 Vaz RG, Mkanda P, Banda R, et al. The role of the polio program infrastructure in response to Ebola virus disease outbreak in Nigeria 2014. J Infect Dis 2016;213 Suppl 3:S140-6.

29 Nigeria Centre for Disease Control. Role of emergency operations centers (EOCs) in outbreak coordination [Internet], 2017. Available: https://ncdc.gov.ng/reports/101/2017-december-week-52

30 NCDC. First annual report of the Nigeria centre for disease control. Fed Minist Heal - Niger Cent Dis Control [Internet] 2016;2017 https:// www.ncdc.gov.ng

31 Nigeria Centre for Disease Control (NCDC)-ICC. Incident activation plan, 2019. Available: https://www.cdc.gov/globalhealth/stories/ 2021/nigerias-effort-to-stop-covid.htm

32 Dalberg Advisors. The journey since the ebola crisis: lessons learned and setting the stage for the next phase of public health emergency operations centers [Internet], 2020. Available: https://dalberg.com/ wp-content/uploads/2020/04/Public-Health-EOCs-The-journeysince-Ebola-March-2020-VF_1.pdf

33 Nigeria Centre for Disease Control (NCDC). Nigeria centre for disease control annual report, 2018. Available: https://ncdc.gov.ng/ themes/common/files/annualreports/18803aba62a09ada4ad84c8d b76c22ea.pdf [Accessed 28 Sep 2021].

34 Nigeria Centre for Disease Control (NCDC). National technical guidelines for integrated disease surveillance and response [Internet], 2019. Available: https://ncdc.gov.ng/themes/common/ docs/protocols/242_1601639437.pdf [Accessed 29 Sep 2021].

35 Nigeria centre for disease control (NCDC). NCDC report (unpublished), 2020. Available: https://www.ncdc.gov.ng/

36 World Health Organization (WHO). Yellow fever - Nigeria [Internet], 2019. Available: https://www.who.int/emergencies/diseaseoutbreak-news/item/09-january-2019-yellow-fever-nigeria-en [Accessed 28 Sep 2021]. 